\title{
[time \& materials] a reheated conversation at the pool
}

\section{klipschutz}

-Dolly, the sheep: the harbinger of Dolly, the sheep.

-Well, hello.

-Thanks to her, "the one and only" will now mean "the one and only" again.

-If you say so. Pressing on, if you had never heard a record, how, then, would a broken one sound?

-Trotting out recycled vintage koans? Look out, Leonard Koan joke ahead!

-They were pressings made of vinyl—flat and jammed with sound, and round and grooved.

-Of late capitalism afternoons, when we were only pintsized critics, we played Frisbee with LPs in vacant lots.

-If I had done the string arrangements and saw you, my heart would have broken in two.

-So here we are, in mufti, cheek to cheek, long in teeth, and still not quite a pair.

-Have faith. I've got laps to do, but then...

-Stop by, if you would, some snowy evening. We'll count sheep. 